\title{
Medical and Endoscopic Management of Gastric Varices
}

\author{
Abdullah M. S. Al-Osaimi, M.D., F.A.C.P., F.A.C.G., A.G.A.F., \\ and Stephen H. Caldwell, M.D. ${ }^{1}$
}

In the past 20 years, our understanding of the pathophysiology and management options among patients with gastric varices $(\mathrm{GV})$ has changed significantly. GV are the most common cause of upper gastrointestinal bleeding in patients with portal hypertension after esophageal varices (EV) and generally have more severe bleeding than EV. In the United States, the majority of GV patients have underlying portal hypertension rather than splenic vein thrombosis. The widely used classifications are the Sarin Endoscopic Classification and the Japanese Vascular Classifications. The former is based on the endoscopic appearance and location of the varices, while the Japanese classification is based on the underlying vascular anatomy. In this article, the authors address the current concepts of classification, epidemiology, pathophysiology, and emerging management options of gastric varices. They describe the stepwise approach to patients with gastric varices, including the different available modalities, and the pearls, pitfalls, and stop-gap measures useful in managing patients with gastric variceal bleed.

KEYWORDS: Gastric varices, portal hypertension, liver cirrhosis, BRTO, TIPS, splenorenal shunt, cyanoacrylate

\begin{abstract}
Objectives: Upon completion of this article, the reader should be able to (1) identify the incidence, etiology, natural history, and classification of gastric varices; (2) identify the initial work-up of patients with acute gastric variceal bleeding; (3) explain the stepwise approach to patients with gastric variceal hemorrhage; (4) list the indications, and the possible benefits and complications, following balloon-occluded retrograde transvenous obliteration.

Accreditation: Tufts University School of Medicine is accredited by the Accreditation Council for Continuing Medical Education to provide continuing medical education for physicians.

Credit: Tufts University School of Medicine designates this journal-based CME activity for a maximum of 1 AMA PRA Category 1 Credit $^{\mathrm{TM}}$. Physicians should claim only the credit commensurate with the extent of their participation in the activity.
\end{abstract}

Gastric varices $(\mathrm{GV})$ are the most common cause of upper gastrointestinal (UGI) bleeding in $\mathrm{pa}^{-}$ tients with portal hypertension after esophageal varices $(\mathrm{EV})$. Bleeding from $\mathrm{GV}$ is generally more severe and is associated with higher morbidity, transfusion requirements and mortality than EV. ${ }^{1}$ If all types of GV are included, the frequency of bleeding is lower than $\mathrm{EV},{ }^{2,3}$ but if 'high risk' GV are considered, the frequency of

\footnotetext{
${ }^{1}$ Division of Gastroenterology and Hepatology, Department of Medicine, University of Virginia Health System, Charlottesville, Virginia. Address for correspondence and reprint requests: Abdullah M. S. Al-Osaimi, M.D., F.A.C.P., F.A.C.G., A.G.A.F., Associate Professor of Medicine and Surgery, Medical Director of Liver Transplantation, Division of Gastroenterology and Hepatology, Deparment of Medicine, University of Virginia Health System, P.O. Box 800708, Charlottesville, VA 22908-0708 (e-mail: aa6h@virginia.edu).
}

Management of Gastric Varices: Endoscopic, BRTO, and TIPS; Guest Editors, Wael E. A. Saad, M.D., F.S.I.R., and Saher S. Sabri, M.D.

Semin Intervent Radiol 2011;28:273-282. Copyright (C) 2011 by Thieme Medical Publishers, Inc., 333 Seventh Avenue, New York, NY 10001, USA. Tel: +1(212) 584-4662.

DOI: http://dx.doi.org/10.1055/s-0031-1284453.

ISSN 0739-9529. 
bleeding is as high as EV. Unfortunately, the approach to prevention of first bleed and rebleed from GV has remained empirical in the absence of large randomized trials.

Much has changed in the past 20 years in our understanding of the pathophysiology and management options among patients with gastric varices. In the United States, the majority of GV patients have underlying portal hypertension rather than splenic vein thrombosis, although exclusion of the latter remains an essential early step in the evaluation. Especially problematic are varices that occur in the fundal area of the stomach. Fundal varices may present as serpiginous obviously vascular structures or sometimes as polypoid masses occasionally resembling a cluster of grapes (Fig. 1). From our experience in a typical tertiary care center, fundal varices are encountered at a rate of $\sim 1-2$ cases per month. These range in severity from acute, active hemorrhage to prior recurrent episodes of bleed-

A

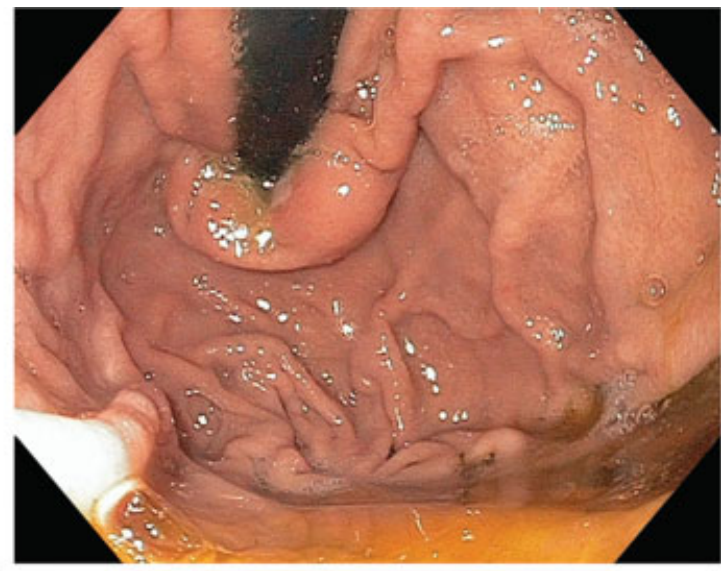

B

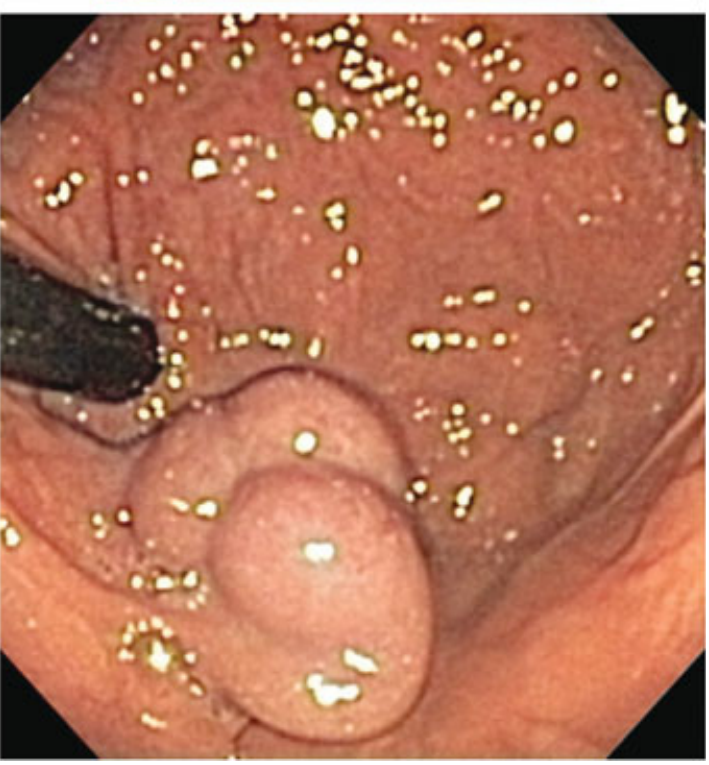

Figure $1(A, B)$ Endoscopic appearance of gastric varices. (A) Demonstrate a type 2 gastro-esophageal varices (GOV) in the cardia, while (B) shows an isolated gastric varix (TGV-1) type 1 in the fundus. ing to incidentally discovered varices sometimes in patients with previously unknown liver disease. Rarely, their somewhat polypoid appearance has led to an errant biopsy in patients not previously known to have liver disease (Fig. 1).

Below, we have addressed current concepts of classification, epidemiology, pathophysiology, and emerging management options of gastric varices. To our knowledge none of the management strategies discussed carry U.S. Food and Drug Administration (FDA) approval with the exception of the Sangstaken-Blakemore tube. Clearly, this is an area in need of carefully planned research in both classification and optimal management triage.

\section{CLASSIFICATION OF GASTRIC VARICES}

The most comprehensive classification of gastric varices divides them into those arising from isolated splenic vein thrombosis (SVT) and those arising from portal hypertension (cirrhotic or noncirrhotic). Gastric varices (GV) in the setting of SVT usually develop in the setting of pancreatitis or local neoplasm in the absence of portal venous hypertension. In our experience, $\mathrm{GV}$ arising due to SVT are much less common than GV due to portal hypertension. ${ }^{3} \mathrm{GV}$ due to SVT usually arise from the short gastric veins running from the hilum of the spleen to the greater curvature aspect of the stomach rather than

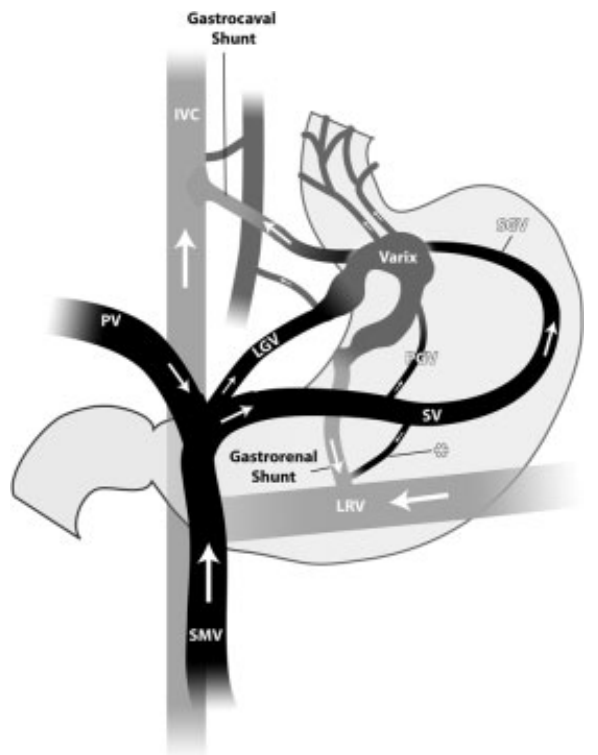

Figure 2 Anatomy of the portal circulation: Gastric varices due to splenic vein thrombosis tend to arise from the short gastric veins running from the hilum of the spleen to the greater curvature aspect of the stomach rather than through spleno- or gastrorenal shunts common with portal hypertensive fundal varices. IVC, inferior vena cava; $P V$, portal vein $S M V$, superior mesenteric vein; LGV, left gastric vein; LRV, left renal vein; PGV, posterior gastric vein; SGV, short gastric vein. (Courtesy of Dr. Saher Sabri.) 
through spleno- or gastrorenal shunts common with portal hypertensive fundal varices (see below; Fig. 2). In addition, SVT-associated GV tend to be multiple and thus sometimes difficult to manage endoscopically due to recurrence of bleeding in alternative short gastric connections. Splenectomy can directly resolve the problem especially in those with pancreatitis, but the presence of underlying neoplasm often precludes effective surgery. Although the patient's history may provide important clues to the underlying disease such as prior bouts of pancreatitis or known GI (pancreatic or gastric) malignancy, early imaging of the splenic vein is helpful in the management of these patients especially when there is uncertainty regarding the presence of liver disease.

Other helpful classification systems, usually applied to patients with liver disease, include the Sarin Endoscopic Classification, which is based on the endo- scopic appearance and location of the varices and the Japanese Vascular Classification system, which is based on underlying vascular anatomy.

The Sarin classification is especially useful in describing the distribution of varices in the distal esophagus and stomach evident by endoscopic examination (Fig. 3). ${ }^{1,3-5}$ According to this classification, fundal varices are included in two groups: type 2 gastroesophageal varices (GOV 2) when the esophageal and fundal varices are present in continuity over the cardia, which might include type 1 isolated gastric varices (IGV 1 ) that are usually isolated gastric fundal varices. Type 1 gastroesophageal varices (GOV 1) are typically a continuation of esophageal varices into the lesser curvature varices. Type 2 isolated gastric varices (IGV 2) are gastric varices at ectopic sites in the stomach outside the cardiofundal region or the first part of the duodenum.
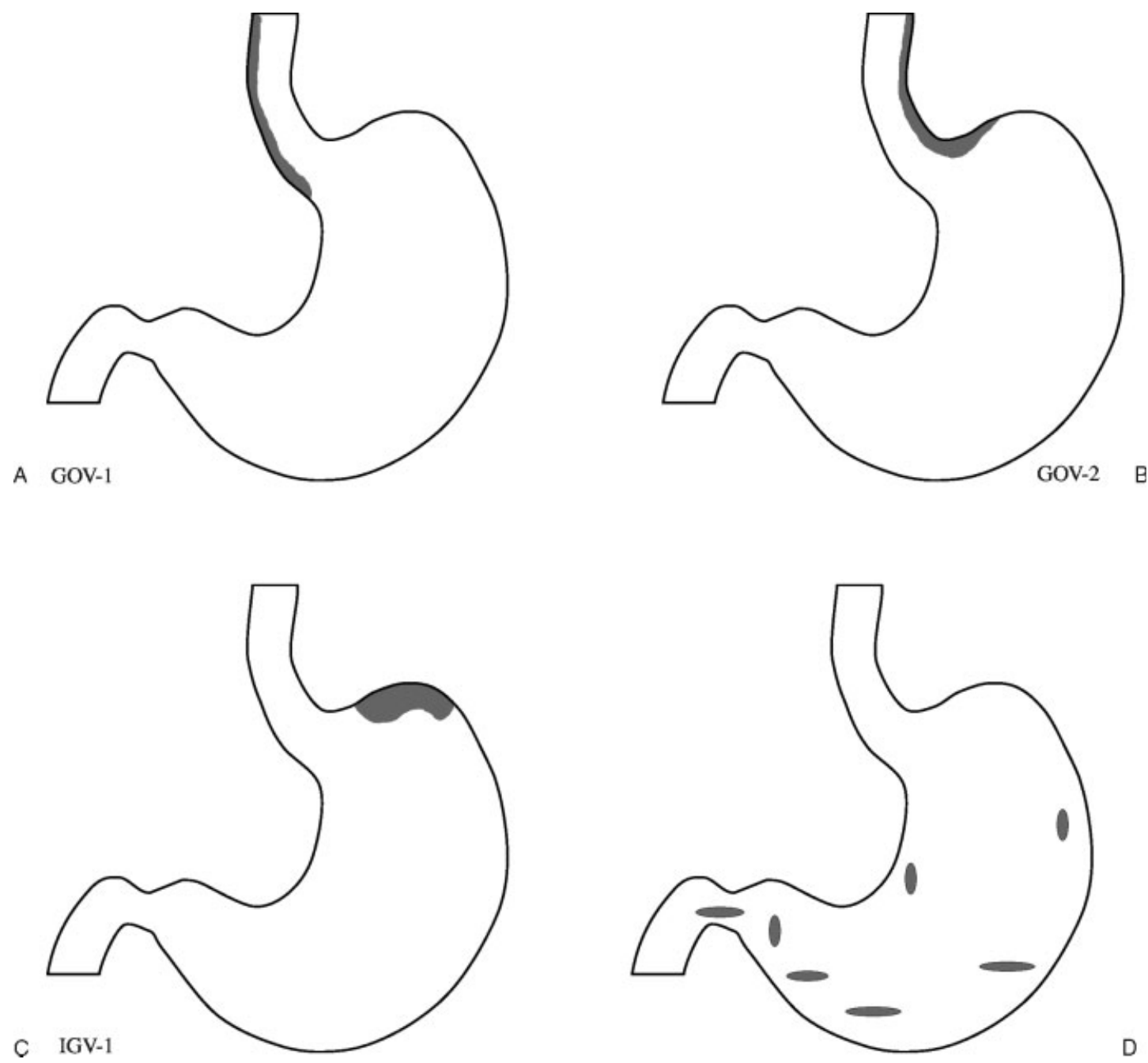

Figure 3 Schematic diagram of Sarin's Classification of Gastric Varices: Fundal varices are included in two of the groups. (A) Type 1 gastroesophageal varices (GOV 1) are typically a continuation of esophageal varices into the lesser curvature varices. (B) Type 2 gastroesophageal varices (GOV 2) when the esophageal and fundal varices are present in continuity over the cardia, (C) which might include type 1 isolated gastric varices (IGV 1) that are usually isolated gastric fundal varices. (D) Type 2 isolated gastric varices (IGV 2) are gastric varices at ectopic sites in the stomach outside the cardiofundal region or the first part of the duodenum. 
Although the Sarin classification scheme offers a useful perspective, it does not address the underlying vascular anatomy. Fundal gastric varices usually arise in part or in total from spleno- or gastrorenal shunts, socalled left-sided portal hypertension. This type of gastric varix often lacks direct vascular continuity with coexisting esophageal varices. Studies from Japan have clearly defined this peculiar anatomy and subsequently classified these varices depending on the underlying tributary vessels. ${ }^{5}$ Type 1 (fundal) gastric varices have a single dominant feeding channel arising from the splenic vein and empty into the left renal vein via the gastric cardia and/or fundus. Type 2 vessels follow a similar course to the left renal vein, but with multiple feeding tributaries (Fig. 2). Although it is likely that intermediate patterns exist, these two dominant patterns are helpful both conceptually and practically with implications for therapeutic alternatives (see below).

\section{EPIDEMIOLOGY AND NATURAL HISTORY OF GASTRIC VARICES}

Accurate incidence and prevalence figures of all types of gastric varices are difficult to determine. Most prior studies have focused on portal hypertension-related gastric varices rather than SVT-related GV. Less is known about cancer-related SVT, but in patients with chronic pancreatitis radiographically evident SVT occurs in $\sim 20 \%$ of patients, although bleeding from associated gastric varices is lower (estimated at $\sim 4 \%$ risk). ${ }^{6,7}$ This relatively low risk is consistent with our prior study where SVT accounted for only 10\% of GV bleeding over $\sim 7$ years. $^{4}$

It is estimated that $30 \%$ of all cirrhosis patients develop variceal bleeding overall and that $\sim 10-20 \%$ of these are gastric., Gastric variceal bleeding is in general more severe and associated with a worse outcome compared with esophageal varices. ${ }^{9}$ Fundal varices (Sarin Class GOV 2 or IGV 1) have been noted to be less common than lesser curvature varices (GOV 1), ${ }^{10}$ but fundal varices accounted for over $80 \%$ of patients with bleeding GV in our series. ${ }^{9}$ This difference may well be due to referral bias, but probably indicates the greater challenge of dealing with bleeding fundal varices

Nonbleeding cardiofundal varices are sometimes encountered during screening endoscopy. The subsequent risk of bleeding from incidentally discovered fundal varices in cirrhosis patients is estimated to be $16 \%, 36 \%$, and $44 \%$ at 1 year, 3 years, and 5 years, respectively. ${ }^{11}$ The size of these varices, the presence of surface red marks and the severity of underlying liver disease (Child-Pugh class) are predictive of bleeding. This raises the issue of prophylactic intervention for incidentally discovered gastric varices, although this question has not yet been fully answered: very little data exists to determine the risk and benefit ratio of preventive intervention.

\section{MANAGEMENT OF BLEEDING GASTRIC (CARDIOFUNDAL) VARICES}

Initial management of GV bleeding involves several diagnostic and therapeutic considerations. Basic measures common to GI bleeding, in general, such as establishment of intravenous access and airway control if the patient is unstable are beyond the focus of this article, but overaggressive volume resuscitation should be avoided as it can exacerbate portal hypertension (discussed below). The diagnosis of cirrhosis may be suspected by prior evaluation or through historical, physical, and laboratory findings; this diagnosis is not always apparent initially. In patients with known or suspected portal hypertension, medical therapy also usually includes antiportal hypertension medications and antibiotic prophylaxis.

\section{Conventional Endoscopic Approaches}

Once stabilized, upper endoscopic examination is usually undertaken as a routine early measure to evaluate upper GI bleeding. It is essential to adequately clear residual blood and clot to identify cardiofundal gastric varices especially when alternative causes of GI bleeding are not evident. Lavage through a typical small-bore nasogastric tube can help, but this is often insufficient and it is common to encounter a clot mixed in the fundus that can obscure the source (Fig. 4). Several strategies can be utilized. If the patient is stable, the procedure may be terminated and administration of prokinetic agents undertaken to promote gastric emptying while also radiographically imaging the portal vasculature and planning a follow-up endoscopy and/or radiologic intervention. However, it is often advisable to undertake clearance of a fundal clot using a large-bore lavage tube (Edlich or Ewald Lavage tubes). Alternatively, newer clot evacuation devices adaptable to the endoscope suction port are sometimes helpful.

Encountering a high-risk GV with recent bleeding or an actively bleeding fundal varix presents a difficult challenge. Conventional endoscopic approaches using sclerosants or banding may be options, although prior studies have demonstrated a relatively high failure rate for acute control and an early rebleeding rate with conventional sclerotherapy. ${ }^{12}$ Jutabha et al reported a comparative trial of sclerotherapy versus banding plus sclerotherapy in acute fundal variceal bleeders. ${ }^{13}$ The study was limited by the very small number of subjects enrolled in each group (6 vs 11), but they showed a high rebleeding rate in both groups (33\% vs $45 \%$, not significant). This and similar studies demonstrated the significant morbidity associated with such endoscopic 


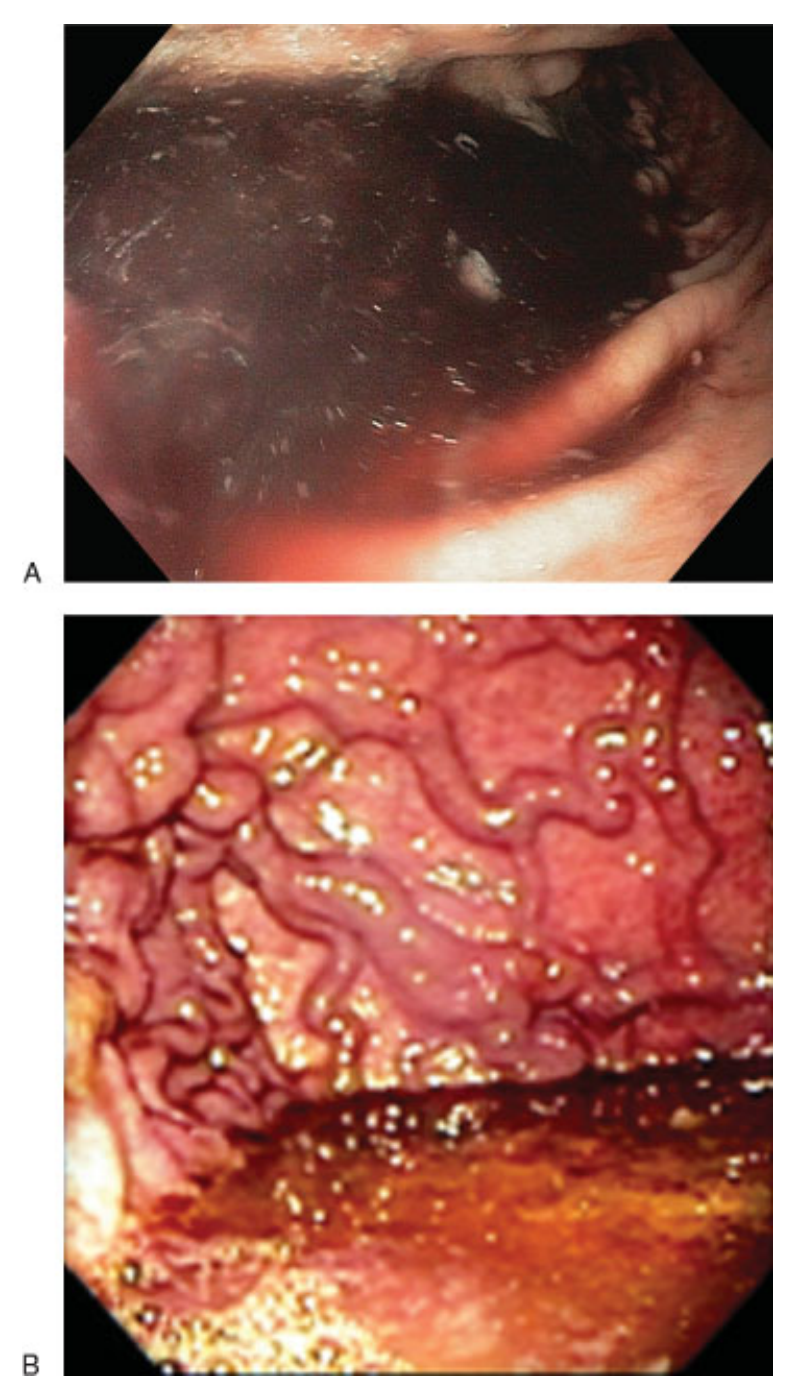

Figure 4 A clot mixed with a bloody pool in the fundus, which can obscure the source.

techniques and enforced the need for alternative approaches. Although not evident by this study, if banding of these vessels is undertaken, we recommend that it be accompanied by concomitant sclerosis to reduce the risk of catastrophic rebleeding should the band prematurely dissociate from these relatively large and deeper channels.

\section{OTHER TEMPORARY MEASURES}

The current conventional approaches poses significant limitations, in addition to the limited availability of alternatives such as cyanoacrylates (see below), temporary measures may be necessary to stabilize the patient especially if active bleeding is encountered. Intragastric balloons (e.g., Sangstaken-Blakemore or Minnesota tubes) are sometime utilized to tamponade these bleeding varices via type of different methods of traction.

The experience with the intragastric tubes has diminished over the years, so we offer several practical points. The gastric balloon needs to be tested to ensure its integrity, we recommend placing the tube in ice to stiffen it and facilitate its passage. Patients are usually intubated for oral passage and various stylets can be employed. Some do recommend passing the tube under direct vision employing a rat-tooth forceps passed through the endoscope to clutch the distal portion of the tube in place. Once in the stomach, a small amount of air (typically $50 \mathrm{cc}$ ) is inflated into the gastric balloon. Then, visualization with an $\mathrm{x}$-ray centered over the xiphoid process to confirm intragastric placement, is recommended. Upon confirmation of the gastric balloon position, air is inflated (the volume of air varies by balloon brand) and traction is applied to effect tamponade, followed by confirmatory x-ray. We usually recommend an orthopedic trapeze bar holder for traction, and a one-liter saline bag rather than a helmet due to problem with airway access, pressure sores, and helmet removal if there is significant edema. The gastric balloon is managed with volume rather than manometric devices and if present, there is usually no need for inflation of the esophageal balloon. Nonetheless, these devices are only temporizing and typically require subsequent disposition to more definitive therapeutic approach. Alternative temporary measures may include recently reported hemoclip placement ${ }^{14}$ (although visualization may be challenging) and possibly procoagulant administration as discussed below.

\section{VOLUME, PLASMA, AND PROCOAGULANTS}

Animal and human studies have established that volume expansion increases portal vein pressure. ${ }^{15-17}$ Variceal bleeding is predominantly portal pressure driven, thus it is evident that minimizing portal pressure is the key objective in managing these patients and similarly avoidance of overaggressive volume resuscitation is warranted. Blood pressure lower than normal is therefore acceptable and relatively lower hematocrit target with packed red blood cell transfusions are the goal. This correlation has led to the target hematocrit level of $21 \%$ from the Baveno IV conference on variceal bleeding, ${ }^{18}$ whereas optimization of platelet function suggests a target of $25 \%$ for hematocrit (due to flow rheology and effective platelet margination). ${ }^{19}$ Renal support may be required for volume control. From the liver transplant experience, maintaining low volumes with its associated low portal pressures played a significant role in controlling bleeding during transplantation. ${ }^{20}$

Because the conventional dose of 2 units of frozen plasma only replace $\sim 10 \%$ of clotting factors and may unfavorably affect portal pressure, the vigilant use of plasma is warranted. ${ }^{21,22}$ We recommend avoiding target levels of international normalized ratio (INR) due to its marked limitations in cirrhosis including poor interlaboratory reproducibility and to the pathophysiology of 
variceal bleeding that is driven primarily by pressure changes as opposed to hemostatic defects. ${ }^{23,24}$ In contrast, more data exist to support platelet administration in this setting. ${ }^{25}$ Although the rupture of a varix is driven by conventional vascular physics, effective hemostasis usually involves components of the clotting system based on the significance of the nipple or platelet plug sign as a high-risk mark that consists of a "white clot" made of platelets and fibrin. ${ }^{26}$ In cirrhosis, platelet levels of around $56,000 / \mathrm{mL}$ or higher are associated with adequate thrombin generation. ${ }^{25}$ These results, though awaiting further clinical translational research, at least serve as a rational basis for target levels of circulating platelets.

The efficacy of synthetic procoagulants in the setting of cirrhosis remains uncertain. Recombinant activated factor VII (rFVIIa) had very limited efficacy in esophageal variceal bleeding outcomes among Child-Pugh C patients using a 42-day mortality composite endpoint with a relatively high dose. ${ }^{27}$ Due to its high cost and the existing data on rFVIIa, we would recommend its consideration only as a latent rescue measure when there is uncontrollable bleeding and by augmenting coagulation clot stabilization might be promoted. Of note, rFVIIa effect depends on sufficient circulating fibrinogen with target levels of $120 \mathrm{mg} / \mathrm{dL}$ or more that might necessitate the administration of cryoprecipitate. Other agents include DDAVP (desmopressin acetate, a synthetic analogue of the natural hormone arginine vasopressin), which was shown in a controlled trial to be ineffective in variceal bleeding. ${ }^{28}$ Further controlled studies comparing these and other treatment modalities are required before synthetic procoagulants can be universally recommended. In the design of studies using synthetic procoagulants, INR should be used with caution given its limitations as a predictor of hemostasis.

\section{TIPS FOR CARDIOFUNDAL VARICEAL BLEEDING}

Given the vascular anatomy of cardiofundal varices (see above and Fig. 2), it is not surprising that a conventional TIPS (transvenous intrahepatic portosystemic shunt), although very effective for esophageal varices, is rather challenging for many gastric varices. ${ }^{29}$ Stent occlusion plays a part in some rebleeding of cardiofundal varices after TIPS placement; however, rebleeding can result from failure of patent intrahepatic shunting to adequately diminish flow in varices arising from the distal splenic vein of the left portal system. ${ }^{30}$ Although the portal venous gradient is strongly predictive in esophageal variceal bleeding, it has a diminished relationship with gastric variceal bleeding, which is an indicator of the different sort of plumbing associated with cardiofundal varices in the left portal system. ${ }^{31}$ This has led to the recommendation that a TIPS in this setting should be accompanied by bland embolization of the gastric varices via a trans-TIPS technique despite the fact that vascular access for effective embolization is often limited (depending on the vascular feeding channels). Also, the patency of both a TIPS and a splenorenal shunt most likely will increase the risk of severe post-TIPS encephalopathy. ${ }^{32}$ Lastly, patients with higher MELD scores and decompensated cirrhosis may not tolerate TIPS. ${ }^{33}$ These concerns have led to the development of alternative approaches such as BRTO (balloonoccluded retrograde transvenous obliteration) by interventional radiology as discussed below. TIPSs are described in detail elsewhere in this issue of Seminars in Interventional Radiology.

\section{CYANOACRYLATES AND GASTRIC VARICEAL BLEEDING}

Cyanoacrylates are a family of compounds that has had a long history of use as a hemostatic agent. These agents encompass a common basic monomeric structure that consists of a reactive cyano (nitrile) group and an alkoxycarbonyl group of variable carbon chain length from which the chemical name derives (octyl-, butyl-, etc.) and which governs the properties of the commercially available forms.

Cyanoacrylate use emerged in Germany in the 1980s as a hemostatic agent for gastric variceal bleeding. ${ }^{34}$ Over the past 30 years cyanoacrylate injection has been established in many parts of the world as the primary means of achieving gastric varix obturation, while its use in the United States continues to be limited. In the meantime, several series of comparative and controlled trials have emerged including our own U.S.based cohort of 92 patients of whom 66 had cardiofundal varices. ${ }^{4,35}$

Cyanoacrylate studies have had significant differences including the type of agent used and the variation in the use of contrast (e.g., lipiodol is utilized to slow polymerization). These variations warrant consideration in interpreting the literature. In an extended 2-year follow-up, a randomized controlled trial (RCT) with cyanoacrylate (enbucrilate mixed 1:1 with lipiodol) versus band ligation, Tan et al demonstrated a $27 \%$ rebleed rate in the cyanoacrylate group versus $63 \%$ rebleeding in the ligation group with no difference in long-term survival. ${ }^{36}$ In another RCT, Lo et al showed a 1 -year rebleeding rate of $15 \%$ with cyanoacrylate (enbucrilate mixed 1:3 with lipiodol) versus $60 \%$ in the band ligation group with a significant survival advantage for the cyanoacrylate group, for the studied period. ${ }^{37}$ In a cohort study comparing cyanoacrylate (enbucrilate mixed with lipiodol 1:1.5) versus a TIPS, Mahadeva et al demonstrated similar rebleeding rates, 
with a slight (nonsignificant) advantage to a TIPS. ${ }^{38}$ In addition, Mahadeva et al showed long-term survival between the groups, but with a $50 \%$ cost reduction in the cyanoacrylate group, which was similar to our own cost analysis comparing these interventions. ${ }^{38-40}$ In contrast to the above study, our cohort comparison study did not detect a difference in rebleeding $(\sim 15 \%)$ or survival at one year $(\sim 70 \%)$ between cyanoacrylate (enbucrilate mixed with ethiodol 1:1) versus a TIPS, but showed increased morbidity mostly due to hepatic encephalopathy that was significantly higher in the TIPS group. ${ }^{40}$ In a more recent RCT of cyanoacrylate versus a TIPS, Lo et al reported a higher rebleeding rate from gastric varices in the cyanoacrylate group (38\%) versus the TIPS group (11\%) with a median follow-up of 33 months, although there was no difference in survival rate. ${ }^{41}$

We recommend the following practical considerations including some methodologic techniques. Among these is the use of the short sigmoidoscope, as this tremendously facilitates maneuvering in the fundus because of its inherent deflection properties; it also decreases the impact of potential scope damage, which is very rare with careful cleaning with an acetone wipe and an endoscopic brush to remove any residual following the glue procedure. Certain injector needle hubs can interact with the cyanoacrylate and thus require in vitro testing to ensure compatibility of the plastic. In addition, we recommend a follow-up endoscopy to assess for residual varices and possible retreatment; however, appropriate intervals of follow-up have not been critically assessed and vary in the literature. This usually depends on the adequacy of the initial treatment and thus will vary between several days to several weeks. Endoscopic ultrasound (Fig. 5) can be very useful to assess for variceal flow occlusion and is likely superior to commonly employed blunt probe palpation. Finally, many experts have called for further multicenter RCTs of cyanoacrylate for gastric varices;

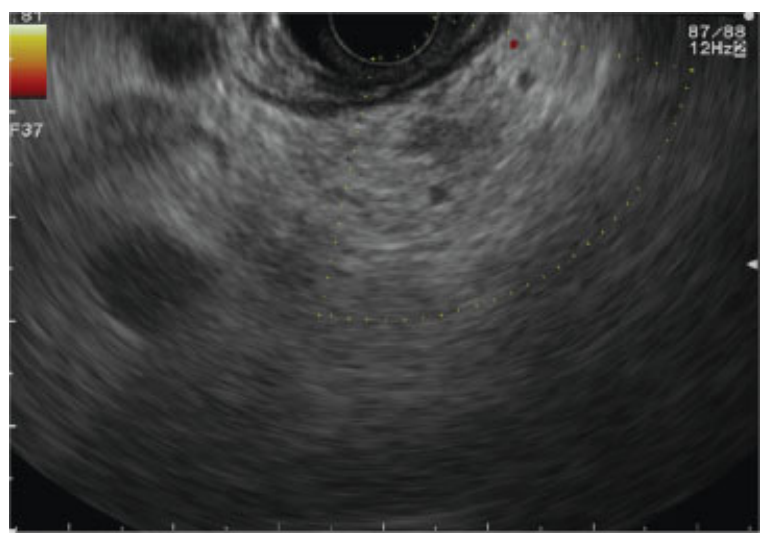

Figure 5 Endoscopic ultrasound with color flow Doppler of obliterated gastric varix postcyanoacrylate glue injection. (Courtesy of Dr. Bryan Sauer.) nevertheless, the absence of a patentable substance limits industry interest as well as the relatively small number of patients will likely require approval as an orphan device if these multicenter RCTs were to happen. Additional endoscopic approaches have been reported, including thrombin injection and endoloop ligation. Intravariceal injection of thrombin has been shown to be effective in the control gastric variceal bleeding with a relatively good success rate of up to 75$100 \%$ and a low rebleeding rate of $7-25 \% .{ }^{42-45}$

\section{BRTO (BALLOON-OCCLUDED RETROGRADE TRANSVENOUS OBLITERATION)}

Cardiofundal gastric varices usually have unique vascular anatomy (spontaneous splenorenal or gastrorenal shunts), thus an approach via the femoral vein and left renal vein is feasible and allows for transvenous obliteration (Fig. 2). BRTO was initially reported from Japan in the $1990 \mathrm{~s},{ }^{46,47}$ this technique has enjoyed increasing utilization worldwide, with a few centers in the United States. Detailed discussions of BRTO are described elsewhere in this issue.

Successful occlusion of the splenorenal shunt with BRTO is associated with increased portal pressure flow to the liver in most patients. ${ }^{48}$ To our knowledge, this phenomenon has not been studied in patients with cyanoacrylate obturation, but may be less likely depending on the magnitude of the occlusion. In BRTO, this phenomenon can be associated with slightly increasing spleen size, exacerbation of ascites, gallbladder wall and intestinal edema, and variably with exacerbation of esophageal varix size. ${ }^{49,50}$ These were not found to be clinically significant in our initial experience with 16 patients, although we have observed transient bacteremia associated with longer balloon occlusion times in one patient who required extensive collateral embolization. ${ }^{51}$

Follow-up strategies or BRTO have yet to be fully determined, but, as with cyanoacrylate therapy, we have found endoscopic ultrasound to be helpful in confirming occlusion of the cardiofundal varices. Presence of residual flow in the varices can be treated with cyanoacrylate with presumably even less risk of systemic embolization due to partial occlusion of the outflow track. Because of the reported possibility of exacerbating esophageal varices, periodic endoscopic examination is recommended. See Fig. 6 for a recommended algorithm for the management of gastric varices. ${ }^{52,53}$

\section{OTHER CONSEQUENCES OF \\ CARDIOFUNDAL VARICES}

Due to the physiology of the spontaneous splenorenal or gastrorenal shunt, it can be expected that these 


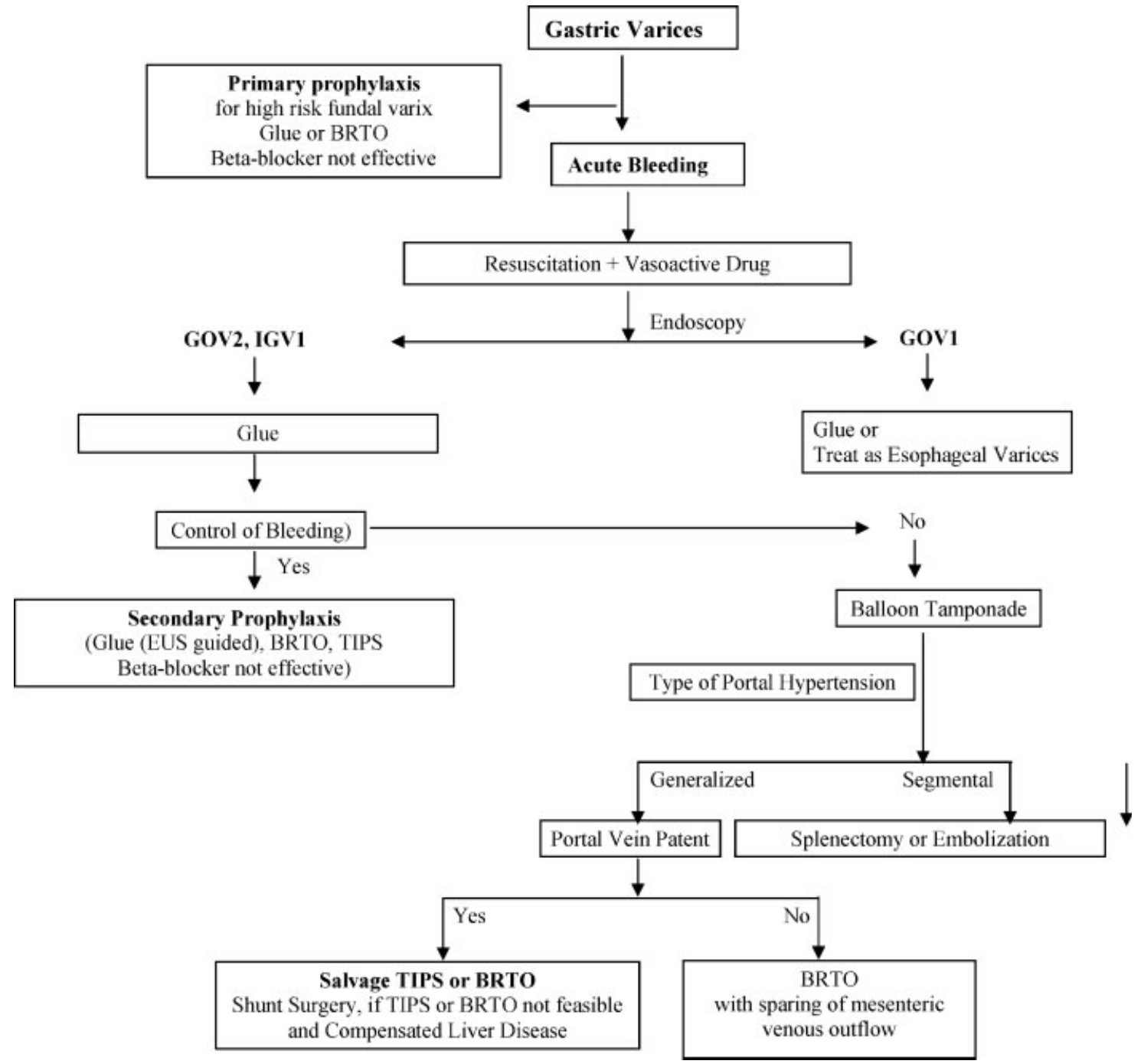

Figure 6 Algorithm for the management of gastric varices.

shunts can function like a TIPS or surgical shunt. In our center we have experienced several patients with nonbleeding cardiofundal varices who present with recurring bouts of severe encephalopathy and minimal or no ascites consistent with portal decompression through such shunts. These patients may respond to occlusion of these shunts utilizing the BRTO approach, although as noted above, this approach would warrant close observation in such patients for sideeffects related to exacerbation of the portal venous gradient. $^{54,55}$

\section{SUMMARY}

Gastric varices $(\mathrm{GV})$ are the most common cause of UGI bleeding in patients with portal hypertension after esophageal varices. In the United States the majority of GV patients have underlying portal hypertension rather than splenic vein thrombosis. Treatment of these patients is usually complex and requires a team approach with defined stepwise management.

\section{ACKNOWLEDGMENTS}

We thank Reem Asseri for the schematics of the gastric varices, and Elizabeth Hespenheide, R.N. and Divyesh Sejpal, M.D. for their initial work on the cyanoacrylate studies.

\section{DISCLOSURE}

Dr. SH Caldwell has disclosed financial support for research from CL Behring; the first author has no financial disclosure or otherwise relating to this manuscript.

\section{REFERENCES}

1. Sarin SK, Kumar A. Gastric varices: profile, classification, and management. Am J Gastroenterol 1989;84(10): 1244-1249

2. Stray N, Jacobsen CD, Rosseland A. Injection sclerotherapy of bleeding oesophageal and gastric varices using a flexible endoscope. Acta Med Scand 1982;211(1-2):125-129 
3. Sarin SK, Lahoti D, Saxena SP, Murthy NS, Makwana UK. Prevalence, classification and natural history of gastric varices: a long-term follow-up study in 568 portal hypertension patients. Hepatology 1992;16(6):13431349

4. Caldwell SH, Hespenheide EE, Greenwald BD, Northup PG, Patrie JT. Enbucrilate for gastric varices: extended experience in 92 patients. Aliment Pharmacol Ther 2007; 26(1):49-59

5. Arakawa M, Masuzaki T, Okuda K. Pathology of fundic varices of the stomach and rupture. J Gastroenterol Hepatol 2002;17(10):1064-1069

6. Agarwal AK, Raj Kumar K, Agarwal S, Singh S. Significance of splenic vein thrombosis in chronic pancreatitis. Am J Surg 2008;196(2):149-154

7. Heider TR, Azeem S, Galanko JA, Behrns KE. The natural history of pancreatitis-induced splenic vein thrombosis. Ann Surg 2004;239(6):876-880; discussion 880-882

8. Ryan BM, Stockbrugger RW, Ryan JM. A pathophysiologic, gastroenterologic, and radiologic approach to the management of gastric varices. Gastroenterology 2004; 126(4):1175-1189

9. Trudeau W, Prindiville T. Endoscopic injection sclerosis in bleeding gastric varices. Gastrointest Endosc 1986;32(4): 264-268

10. Chey WD, Elta GH. Natural history of gastric varices. Gastroenterology 1993;105(2):599-602

11. Kim T, Shijo H, Kokawa H, et al. Risk factors for hemorrhage from gastric fundal varices. Hepatology 1997;25(2):307-312

12. Sarin SK. Long-term follow-up of gastric variceal sclerotherapy: an eleven-year experience. Gastrointest Endosc 1997;46(1):8-14

13. Jutabha R, Jensen DM, Kovacs TOG, et al. Initial results of combination banding and sclerotherapy compared to sclerotherapy alone for bleeding gastric varices. Gastrointest Endosc 1998;47:AB86

14. Scapa E. Treating gastrointestinal bleeding with endoscopic hemoclips. Surg Laparosc Endosc 1997;7(2):94-96

15. Kravetz D, Bosch J, Arderiu M, Pilar Pizcueta M, Rodés J. Hemodynamic effects of blood volume restitution following a hemorrhage in rats with portal hypertension due to cirrhosis of the liver: influence of the extent of portal-systemic shunting. Hepatology 1989;9(6):808-814

16. Castañeda B, Morales J, Lionetti R, et al. Effects of blood volume restitution following a portal hypertensive-related bleeding in anesthetized cirrhotic rats. Hepatology 2001; 33(4):821-825

17. Villanueva C, Ortiz J, Miñana J, et al. Somatostatin treatment and risk stratification by continuous portal pressure monitoring during acute variceal bleeding. Gastroenterology 2001;121(1):110-117

18. de Franchis R. Evolving consensus in portal hypertension. Report of the Baveno IV consensus workshop on methodology of diagnosis and therapy in portal hypertension. J Hepatol 2005;43(1):167-176

19. Gabriel DA, Li X, Monroe DMIII III, Roberts HR. Recombinant human factor VIIa (rFVIIa) can activate factor FIX on activated platelets. J Thromb Haemost 2004;2(10): 1816-1822

20. Porte RJ, Molenaar IQ, Begliomini B, et al; EMSALT Study Group. Aprotinin and transfusion requirements in orthotopic liver transplantation: a multicentre randomised double-blind study. Lancet 2000;355(9212):1303-1309
21. Westerkamp AC, Lisman T, Porte RJ. How to minimize blood loss during liver surgery in patients with cirrhosis. HPB (Oxford) 2009;11(6):453-458

22. Youssef WI, Salazar FD, Dasarathy S, Beddow T, Mullen $\mathrm{KD}$. Role of fresh frozen plasma infusion in correction of coagulopathy of chronic liver disease: a dual phase study. Am J Gastroenterol 2003;98(6):1391-1394

23. Porte RJ, Lisman T, Tripodi A, Caldwell SH, Trotter JF; Coagulation in Liver Disease Study Group. The international normalized ratio (INR) in the MELD score: problems and solutions. Am J Transplant 2010;10(6):1349-1353

24. Trotter JF, Olson J, Lefkowitz J, Smith AD, Arjal R, Kenison $\mathrm{J}$. Changes in international normalized ratio (INR) and model for endstage liver disease (MELD) based on selection of clinical laboratory. Am J Transplant 2007;7(6):1624-1628

25. Tripodi A, Primignani M, Chantarangkul V, et al. Thrombin generation in patients with cirrhosis: the role of platelets. Hepatology 2006;44(2):440-445

26. Hou MC, Lin HC, Kuo BI, Lee FY, Schmidt CM, Lee SD. Clinical implications of the white nipple sign and its role in the diagnosis of esophageal variceal hemorrhage. Am J Gastroenterol 1996;91(10):2103-2109

27. Bosch J, Thabut D, Albillos A, et al; International Study Group on rFVIIa in UGI Hemorrhage. Recombinant factor VII for variceal bleeding in patients with advanced cirrhosis: a randomized, controlled trial. Hepatology 2008;47(5):16041614

28. de Franchis R, Arcidiacono PG, Carpinelli L, et al. Randomized controlled trial of desmopressin plus terlipressin vs. terlipressin alone for the treatment of acute variceal hemorrhage in cirrhotic patients: a multicenter, double-blind study. New Italian Endoscopic Club. Hepatology 1993;18(5): 1102-1107

29. Sanyal AJ, Freedman AM, Luketic VA, et al. Transjugular intrahepatic portosystemic shunts compared with endoscopic sclerotherapy for the prevention of recurrent variceal hemorrhage. A randomized, controlled trial. Ann Intern Med 1997;126(11):849-857

30. Barange K, Péron JM, Imani K, et al. Transjugular intrahepatic portosystemic shunt in the treatment of refractory bleeding from ruptured gastric varices. Hepatology 1999;30(5):11391143

31. Tripathi D, Therapondos G, Jackson E, Redhead DN, Hayes PC. The role of the transjugular intrahepatic portosystemic stent shunt (TIPSS) in the management of bleeding gastric varices: clinical and haemodynamic correlations. Gut 2002; 51(2):270-274

32. Henderson JM, Boyer TD, Kutner MH, et al; DIVERT Study Group. Distal splenorenal shunt versus transjugular intrahepatic portal systematic shunt for variceal bleeding: a randomized trial. Gastroenterology 2006;130(6):1643-1651

33. Ferral H, Gamboa P, Postoak DW, et al. Survival after elective transjugular intrahepatic portosystemic shunt creation: prediction with model for end-stage liver disease score. Radiology 2004;231(1):231-236

34. Soehendra N, Grimm H, Nam VC, Berger B. N-butyl-2cyanoacrylate: a supplement to endoscopic sclerotherapy. Endoscopy 1987;19(6):221-224

35. Rengstorff DS, Binmoeller KF. A pilot study of 2-octyl cyanoacrylate injection for treatment of gastric fundal varices in humans. Gastrointest Endosc 2004;59(4):553-558

36. Tan PC, Hou MC, Lin HC, et al. A randomized trial of endoscopic treatment of acute gastric variceal hemorrhage: 
N-butyl-2-cyanoacrylate injection versus band ligation. Hepatology 2006;43(4):690-697

37. Lo GH, Lai KH, Cheng JS, Chen MH, Chiang HT. A prospective, randomized trial of butyl cyanoacrylate injection versus band ligation in the management of bleeding gastric varices. Hepatology 2001;33(5):1060-1064

38. Mahadeva S, Bellamy MC, Kessel D, Davies MH, Millson CE. Cost-effectiveness of N-butyl-2-cyanoacrylate (histoacryl) glue injections versus transjugular intrahepatic portosystemic shunt in the management of acute gastric variceal bleeding. Am J Gastroenterol 2003;98(12):2688-2693

39. Greenwald BD, Caldwell SH, Hespenheide EE, et al. N-2butyl-cyanoacrylate for bleeding gastric varices: a United States pilot study and cost analysis. Am J Gastroenterol 2003;98(9): 1982-1988

40. Procaccini NJ, Al-Osaimi AM, Northup P, Argo C, Caldwell SH. Endoscopic cyanoacrylate versus transjugular intrahepatic portosystemic shunt for gastric variceal bleeding: a single-center U.S. analysis. Gastrointest Endosc 2009; 70(5):881-887

41. Lo GH, Liang HL, Chen WC, et al. A prospective, randomized controlled trial of transjugular intrahepatic portosystemic shunt versus cyanoacrylate injection in the prevention of gastric variceal rebleeding. Endoscopy 2007; 39(8):679-685

42. Williams SG, Peters RA, Westaby D. Thrombin-an effective treatment for gastric variceal haemorrhage. Gut 1994;35(9):1287-1289

43. Przemioslo RT, McNair A, Williams R. Thrombin is effective in arresting bleeding from gastric variceal hemorrhage. Dig Dis Sci 1999;44(4):778-781

44. Yang WL, Tripathi D, Therapondos G, Todd A, Hayes PC. Endoscopic use of human thrombin in bleeding gastric varices. Am J Gastroenterol 2002;97(6):1381-1385

45. Ramesh J, Limdi JK, Sharma V, Makin AJ. The use of thrombin injections in the management of bleeding gastric varices: a single-center experience. Gastrointest Endosc 2008; 68(5):877-882
46. Kanagawa H, Mima S, Kouyama H, Gotoh K, Uchida T, Okuda K. Treatment of gastric fundal varices by balloonoccluded retrograde transvenous obliteration. J Gastroenterol Hepatol 1996;11(1):51-58

47. Matsumoto A, Hamamoto N, Nomura T, et al. Balloonoccluded retrograde transvenous obliteration of high risk gastric fundal varices. Am J Gastroenterol 1999;94(3):643-649

48. Tanihata $H$, Minamiguchi $H$, Sato $M$, et al. Changes in portal systemic pressure gradient after balloon-occluded retrograde transvenous obliteration of gastric varices and aggravation of esophageal varices. Cardiovasc Intervent Radiol 2009;32(6):1209-1216

49. Cho SK, Shin SW, Do YS, et al. Development of thrombus in the major systemic and portal veins after balloon-occluded retrograde transvenous obliteration for treating gastric variceal bleeding: its frequency and outcome evaluation with CT. J Vasc Interv Radiol 2008;19(4):529-538

50. Cho SK, Shin SW, Yoo EY, et al. The short-term effects of balloon-occluded retrograde transvenous obliteration, for treating gastric variceal bleeding, on portal hypertensive changes: a CT evaluation. Korean J Radiol 2007;8(6):520-530

51. Sabri SS, Swee W, Turba UC, et al. Bleeding gastric varices obliteration with balloon-occluded retrograde transvenous obliteration using sodium tetradecyl sulfate foam. J Vasc Interv Radiol 2011;22(3):309-316; quiz 316

52. Sarin SK, Mishra SR. Endoscopic therapy for gastric varices. Clin Liver Dis 2010;14(2):263-279

53. Irani S, Kowdley K, Kozarek R. Gastric varices: an updated review of management. J Clin Gastroenterol 2011;45(2): 133-148

54. Sakurabayashi S, Sezai S, Yamamoto Y, Hirano M, Oka H. Embolization of portal-systemic shunts in cirrhotic patients with chronic recurrent hepatic encephalopathy. Cardiovasc Intervent Radiol 1997;20(2):120-124

55. Fukuda T, Hirota S, Sugimura K. Long-term results of balloon-occluded retrograde transvenous obliteration for the treatment of gastric varices and hepatic encephalopathy. J Vasc Interv Radiol 2001;12(3):327-336 